\title{
A prospective study of the impact of serial troponin measurements on the diagnosis of myocardial infarction and hospital and six-month mortality in patients admitted to ICU with non-cardiac diagnoses
}

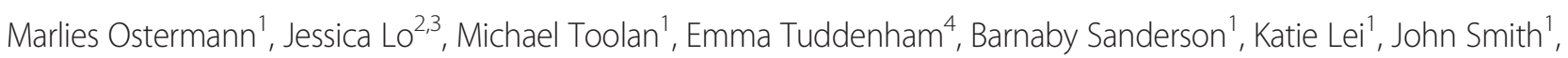
Anna Griffiths ${ }^{5}$, lan Webb ${ }^{5}$, James Coutts ${ }^{5}$, John Chambers ${ }^{5}$, Paul Collinson ${ }^{6}$, Janet Peacock ${ }^{2,3}$, David Bennett ${ }^{1}$ and David Treacher ${ }^{1 *}$

\begin{abstract}
Introduction: Troponin T (cTnT) elevation is common in patients in the Intensive Care Unit (ICU) and associated with morbidity and mortality. Our aim was to determine the epidemiology of raised CTnT levels and contemporaneous electrocardiogram (ECG) changes suggesting myocardial infarction (MI) in ICU patients admitted for non-cardiac reasons.
\end{abstract}

Methods: CTnT and ECGs were recorded daily during week 1 and on alternate days during week 2 until discharge from ICU or death. ECGs were interpreted independently for the presence of ischaemic changes. Patients were classified into four groups: (i) definite $\mathrm{Ml}$ (cTnT $\geq 15 \mathrm{ng} / \mathrm{L}$ and contemporaneous changes of Ml on ECG), (ii) possible MI (cTnT $\geq 15 \mathrm{ng} / \mathrm{L}$ and contemporaneous ischaemic changes on ECG), (iii) troponin rise alone (cTnT $\geq 15 \mathrm{ng} / \mathrm{L}$ ), or (iv) normal. Medical notes were screened independently by two ICU clinicians for evidence that the clinical teams had considered a cardiac event.

Results: Data from 144 patients were analysed (42\% female; mean age 61.9 (SD 16.9)). A total of 121 patients (84\%) had at least one CTnT level $\geq 15 \mathrm{ng} / \mathrm{L}$. A total of 20 patients (14\%) had a definite Ml, 27\% had a possible $\mathrm{Ml}, 43 \%$ had a CTNT rise without contemporaneous ECG changes, and 16\% had no cTNT rise. ICU, hospital and 180-day mortality was significantly higher in patients with a definite or possible Ml.

Only 20\% of definite Mls were recognised by the clinical team. There was no significant difference in mortality between recognised and non-recognised events.

At the time of CTNT rise, 100 patients (70\%) were septic and 58\% were on vasopressors. Patients who were septic when CTNT was elevated had an ICU mortality of $28 \%$ compared to $9 \%$ in patients without sepsis. ICU mortality of patients who were on vasopressors at the time of cTnT elevation was $37 \%$ compared to $1.7 \%$ in patients not on vasopressors.

Conclusions: The majority of critically ill patients (84\%) had a cTnT rise and $41 \%$ met criteria for a possible or definite $\mathrm{Ml}$ of whom only $20 \%$ were recognised clinically. Mortality up to 180 days was higher in patients with a cTnT rise.

\footnotetext{
* Correspondence: David.Treacher@gstt.nhs.uk

'Department of Critical Care, King's College London, Guy's \& St Thomas'

Foundation Hospital, London, UK

Full list of author information is available at the end of the article
} 


\section{Introduction}

Cardiac troponin ( $\mathrm{cTn}$ ) is a sensitive and specific marker of myocardial injury and is firmly established in the diagnosis of myocardial infarction (MI) [1]. Troponin elevation is common in patients in the intensive care unit (ICU) (12 to 85\%) and associated with increased morbidity, mortality and length of stay [2-7]. There are multiple potential aetiologies of troponin rises, including cardiac causes, such as acute coronary syndromes (ACS), MI, heart failure and pericarditis/myocarditis, and non-cardiac causes, such as sepsis, pulmonary disease, renal impairment and intracranial events, but MI and sepsis are the most important causes in this patient cohort $[8,9]$.

There is evidence that the mechanism of troponin release and the prognostic significance of an elevated troponin level vary depending on the underlying cause. In patients with severe sepsis, troponin release can occur in the absence of flow-limiting coronary artery disease and may be due to transient loss in membrane integrity with subsequent troponin leakage or microvascular thrombotic injury $[4,10,11]$. Ver Elst et al. performed post-mortem examinations in patients with septic shock and found similar non-specific changes in troponin positive and troponin negative patients, including elongated myocardial fibers and interstitial oedema but no evidence of MI [12]. Other studies not restricted to sepsis showed that 36 to $71 \%$ of patients with elevated troponin levels had ischaemic changes on electrocardiogram (ECG) $[2,6,13,14]$, which therefore defines them as MIs by the consensus criteria [1].

In clinical practice, the diagnosis of MI in ICU patients is complicated by the frequent absence of clinical symptoms, the presence of confounding comorbidities and the difficulty of interpreting ECG changes and troponin elevation in the context of critical illness. Two studies by Lim et al., conducted at a single centre, found that MI, as defined by raised troponin levels and contemporaneous ischaemic ECG changes, occurred in 26 to 36\% of ICU patients [2,14]. Hospital mortality in patients with MI was $43 \%$, compared to $27 \%$ in those with elevated troponin only. More than half of the MIs diagnosed by prospective screening were missed by the clinical team, although the associated mortality was similar irrespective of whether the events were recognised or not $39 \%$ vs. $35 \%$ ICU mortality and $50 \%$ vs. $35 \%$ hospital mortality, respectively, with non-significant $P$-values).

Our objectives were i) to repeat the study by Lim and colleagues in consecutive patients admitted for noncardiac reasons to a mixed medical-surgical ICU in the $\mathrm{UK}$, ii) to determine the epidemiology and outcomes of recognised and unrecognised myocardial events as diagnosed by expert cardiologists, and iii) to investigate the association between troponin elevation and contemporaneous sepsis and vasopressor use.

\section{Material and methods Patients}

We conducted a prospective observational study in the 30-bed, level 3 multi-disciplinary adult ICU at the St Thomas' site of Guy's \& St Thomas' Hospital, a large tertiary referral centre in London, UK. The ICU is a closed ICU led by full time Intensive Care consultants. During a seven-month period between June and December 2010, consecutive adult patients (age $\geq 18$ years) were recruited. Patients with a high probability of cardiac injury or a primary cardiac diagnosis at ICU admission were excluded, specifically those with a clinical diagnosis of MI or out-of-hospital cardiac arrest, patients who were post-cardiac surgery or cardiac intervention and patients admitted following thoracic trauma with a high likelihood of myocardial injury. Patients were also excluded if they had been transferred from an external ICU following $>24$ hours stay, had previously been admitted to the ICU during their current hospital stay or were expected to remain in ICU for $<48$ hours.

\section{Sample collection}

During the first week, we measured troponin $\mathrm{T}$ and routine blood tests and performed an ECG on a daily basis. During the second week, troponin $\mathrm{T}$ and ECGs were taken on alternate days until discharge from ICU, death or for up to two weeks from admission, whichever occurred first. Serial ECGs taken for research purposes were stored in a secure locker in the research office. Neither the troponin results nor the ECGs were available to the clinical team caring for the patient. However, the clinical team was allowed to perform ECGs and troponin measurements separately as clinically indicated.

\section{Data collection}

At enrolment, baseline demographic data (age, gender, ethnicity), known cardiovascular risk factors (ischaemic heart disease (IHD), diabetes, hypertension, any other type of vascular disease), Acute Physiology and Chronic Health Evaluation (APACHE) II score, and admission diagnosis were recorded.

We recorded use of vasopressors and the presence of sepsis (defined as the presence of $\geq 2$ criteria of systemic inflammatory response syndrome (SIRS) and confirmed or suspected diagnosis of infection) at baseline and daily throughout the study period.

\section{Laboratory analyses}

Blood samples for troponin analysis were stored at $-70^{\circ} \mathrm{C}$ until batch analysis in the biochemistry laboratory at $\mathrm{St}$ George's University Hospital, London. Troponin T was measured using the Roche electrochemiluminescent high sensitivity sandwich immunoassay on the Elecsys 2010 (Roche Diagnostics, Indianapolis, IN, USA). The quoted 
analytical range is 0.003 to $10 \mu \mathrm{g} / \mathrm{L}$, total coefficients of variations are 1.5 to $3.4 \%$ (measured between 0.024 to $2.665 \mu \mathrm{g} / \mathrm{L}$ ) and reference range is less than $15 \mathrm{ng} / \mathrm{L}$ $\left(99^{\text {th }}\right.$ percentile) [15]. Other laboratory tests were undertaken at Guy's \& St Thomas' Hospital.

\section{Interpretation of troponin levels and diagnosis of myocardial events}

Troponin T levels were interpreted as raised if $\geq 15 \mathrm{ng} / \mathrm{L}$, corresponding to the $99^{\text {th }}$ population percentile [1]. Serial ECGs were analysed independently by two senior cardiologists (JCo, IW) at study completion and evaluated for the presence of ischaemic changes consistent with an acute MI using pre-defined criteria. In case of discrepancy, adjudication was undertaken by a third senior cardiologist (JCh). All cardiologists were blinded to the troponin results and clinical details of the patients.

The diagnosis of an acute myocardial event was based on the presence of elevated troponin $\mathrm{T} \geq 15 \mathrm{ng} / \mathrm{L}$ and contemporaneous ischaemic ECG changes according to the European Society of Cardiology/American College of Cardiology Committee criteria [1]. Patients were classified into four groups: (i) definite MI, with troponin $\mathrm{T} \geq 15 \mathrm{ng} / \mathrm{L}$ and contemporaneous ECG changes consistent with MI, (ii) possible MI, with troponin $\mathrm{T} \geq 15 \mathrm{ng} / \mathrm{L}$ and contemporaneous ischaemic changes on ECG but not fulfilling criteria for definite MI, (iii) troponin $\mathrm{T}$ rise alone, and (iv) normal, with troponin $\mathrm{T}<15 \mathrm{ng} / \mathrm{L}$ and not falling into the other three groups.

Medical notes were retrospectively reviewed independently by two ICU clinicians (DT, MO) for evidence that the clinical team had considered the possibility of an acute cardiac event based on ECG and/or troponin criteria performed for clinical reasons and/or explicit entries in the medical notes. Based on these results, we distinguished between clinically recognised and unrecognised acute myocardial events.

\section{Outcomes}

All patients were followed up for 180 days. The main outcomes were mortality at discharge from ICU and hospital and at 180 days, and length of stay in ICU and hospital. In addition, we compared the outcomes of patients with clinically recognised and unrecognised cardiac events.

\section{Ethics}

The study was approved by the Research Ethics Committee (REC) at St Thomas' Hospital. If a patient had the capacity, written informed consent was obtained from the patient prior to enrolment. If a patient did not have the capacity to consent as a result of the underlying critical illness or sedating medication, the opinion of a personal consultee was sought in accordance with Section 32 of the Mental Capacity Act 2005 (UK). In all cases, a personal consultee was someone with a close personal relationship whom the person who lacked capacity would trust with important decisions about their welfare, for example, a spouse or partner, adult child, parent or a close friend. The personal consultee was asked to consider whether the person who lacked capacity would be content to take part or whether doing so might upset them, and to give their opinion on what the past and present wishes and feelings the person who lacked capacity would have been about taking part in the study. In cases where a personal consultee was consulted, patients were asked to give informed consent retrospectively once they regained capacity. If retrospective consent was declined, all collected samples and ECGs were discarded. The REC waived the need for any additional consent in case retrospective consent could not be obtained due to death or lack of capacity. The REC felt it appropriate that these patients were included in the analysis.

\section{Statistics}

Mean and standard deviation are reported for continuous data. Median and inter-quartile range (IQR) are reported for skewed data such as length of stay. Binary data are reported as frequency and percentage values. Pairwise comparisons were made among three groups: MI (combining the definite MI and possible MI groups), elevated troponin $\mathrm{T}$ only, and normal (that is, no troponin elevation). For baseline data, the t-test or the MannWhitney $U$ test were used as appropriate to analyse continuous data; Pearson's Chi-square or Fisher's Exact Test were used as appropriate in case of categorical variables. The Bonferroni method was used where there was multiple significance testing: a $P$-value of less than 0.016 $(0.05 / n$, where $n$ is the number of tests) was considered statistically significant. Multivariable regression was used to examine the relationships among raised troponin, MI and patient outcome after adjusting for imbalances in baseline factors. Principal component analysis was used to reduce the number of covariates because the sample is small. Similarly, multivariable regression was used to examine the difference on patient outcome between clinically recognised and unrecognised cardiac events. All analyses were done using Stata v.12 (StataCorp, College Station, Texas, USA).

\section{Results}

\section{Patient population}

Over a seven-month period, 165 eligible patients were identified and approached. In 16 cases, the patient or personal consultee declined consent or assent. The remaining 149 patients were enrolled in the study; however, 5 of these patients were excluded from the final analysis. Reasons for exclusion were the presence of ACS on admission to ICU which had not been recognised by 
the research team $(n=3)$ and transfer to a specialist ICU in another hospital for advanced liver and neurosurgical care within 48 hours of admission $(n=2)$.

The mean age of the remaining 144 patients was 61.9 $(\mathrm{SD}=16.9) ; 42.4 \%$ were female (Table 1$)$. The mean APACHE II score at admission was 19.4 ( $\mathrm{SD}=6.2)$. Acute renal replacement therapy was initiated in 48 patients (32\%). The remaining 101 patients had a median serum creatinine $74 \mu \mathrm{mol} / \mathrm{L}$ (range 22 to 345 ).

\section{Prevalence of troponin rise}

The majority of patients (121 patients (84\%)) had at least one elevated troponin $\mathrm{T}$ result (cTnT $\geq 15 \mathrm{ng} / \mathrm{L}$ ). Of these, 20 (14\%) had contemporaneous ECG changes consistent

Table 1 Demographics and baseline data

\begin{tabular}{|c|c|c|c|c|c|c|}
\hline & $\begin{array}{l}\text { Total } \\
(n=144)\end{array}$ & $\begin{array}{l}\text { Definite MI } \\
(\mathrm{n}=20)\end{array}$ & $\begin{array}{l}\text { Possible MI } \\
(\mathrm{n}=39)\end{array}$ & $\begin{array}{l}\text { Elevated cTnT only } \\
(n=62)\end{array}$ & $\begin{array}{l}\text { Normal (No cTnT elevation) } \\
(n=23)\end{array}$ & $P$-value \\
\hline \multirow[t]{3}{*}{ Age, mean (SD) } & $61.9(16.9)$ & $62.3(14.1)$ & $67.6(15.6)$ & $64.3(15.2)$ & $45.4(16.6)$ & $\begin{array}{l}\text { MI (definite or possible) } \\
\text { vs elevated cTnT; }<0.001\end{array}$ \\
\hline & & & & & & $\begin{array}{l}\text { MI (definite or possible) } \\
\text { vs normal: }<0.001\end{array}$ \\
\hline & & & & & & Elevated cTnT vs normal: $<0.001$ \\
\hline \multirow[t]{3}{*}{ Female, n (\%) } & $61(42 \%)$ & $8(40 \%)$ & $16(42 \%)$ & $30(48 \%)$ & 7 (30.4\%) & $\begin{array}{l}\text { MI (definite or possible) } \\
\text { vs elevated cTnT; } 0.39\end{array}$ \\
\hline & & & & & & $\begin{array}{l}\text { MI (definite or possible) } \\
\text { vs normal: } 0.39\end{array}$ \\
\hline & & & & & & Elevated cTnT vs normal: 0.14 \\
\hline \multirow[t]{3}{*}{ White ethnicity, n (\%) } & $123(85.4 \%)$ & $17(85 \%)$ & $34(87 \%)$ & $54(87 \%)$ & $18(78.3 \%)$ & $\begin{array}{l}\text { MI (definite or possible) } \\
\text { vs elevated cTnT; } 0.92\end{array}$ \\
\hline & & & & & & $\begin{array}{l}\text { MI (definite or possible) } \\
\text { vs normal: } 0.36\end{array}$ \\
\hline & & & & & & Elevated cTnT vs normal: 0.32 \\
\hline \multirow[t]{3}{*}{$\begin{array}{l}\text { APACHE II score, } \\
\text { mean (SD) }\end{array}$} & $19.4(6.23)$ & $18.8(5.47)$ & $20.5(5.84)$ & $21.2(5.84)$ & $13.2(4.60)$ & $\begin{array}{l}\text { MI (definite or possible) } \\
\text { vs elevated cTnT; } 0.20\end{array}$ \\
\hline & & & & & & $\begin{array}{l}\text { MI (definite or possible) } \\
\text { vs normal: }<0.001\end{array}$ \\
\hline & & & & & & Elevated cTnT vs normal: $<0.001$ \\
\hline \multicolumn{7}{|l|}{ Past medical history } \\
\hline \multirow[t]{3}{*}{$\begin{array}{l}\text { Ischaemic heart } \\
\text { disease, n (\%) }\end{array}$} & $24(16.7 \%)$ & $5(25 \%)$ & $8(21 \%)$ & $10(16 \%)$ & $1(4.35 \%)$ & $\begin{array}{l}\text { MI (definite or possible) } \\
\text { vs elevated cTnT; } 0.41\end{array}$ \\
\hline & & & & & & $\begin{array}{l}\text { MI (definite or possible) } \\
\text { vs normal: } 0.099\end{array}$ \\
\hline & & & & & & Elevated cTnT vs normal: 0.28 \\
\hline \multirow[t]{3}{*}{ Hypertension, n (\%) } & $52(36.1 \%)$ & $8(40 \%)$ & $23(59 \%)$ & $19(31 \%)$ & $2(9 \%)$ & $\begin{array}{l}\text { MI (definite or possible) } \\
\text { vs elevated cTnT; } 0.014\end{array}$ \\
\hline & & & & & & $\begin{array}{l}\text { MI (definite or possible) } \\
\text { vs normal: }<0.001\end{array}$ \\
\hline & & & & & & Elevated cTnT vs normal: 0.048 \\
\hline \multirow[t]{3}{*}{ Diabetes, n (\%) } & $41(28.5 \%)$ & $8(40 \%)$ & $14(36 \%)$ & $18(29 \%)$ & $1(4 \%)$ & $\begin{array}{l}\text { MI (definite or possible) } \\
\text { vs elevated cTnT; } 0.34\end{array}$ \\
\hline & & & & & & $\begin{array}{l}\text { MI (definite or possible) } \\
\text { vs normal: } 0.002\end{array}$ \\
\hline & & & & & & Elevated cTnT vs normal: 0.018 \\
\hline \multirow[t]{3}{*}{$\begin{array}{l}\text { Any type of vascular } \\
\text { disease, } \mathrm{n}(\%)\end{array}$} & $29(20.1 \%)$ & $4(20 \%)$ & $12(32 \%)$ & $12(19 \%)$ & $1(4 \%)$ & $\begin{array}{l}\text { MI (definite or possible) } \\
\text { vs elevated cTnT; } 0.31\end{array}$ \\
\hline & & & & & & $\begin{array}{l}\text { MI (definite or possible) } \\
\text { vs normal: } 0.031\end{array}$ \\
\hline & & & & & & Elevated cTnT vs normal: 0.17 \\
\hline
\end{tabular}


with a definite MI, 39 (27\%) had ECG changes consistent with a possible MI and 62 (43\%) had elevated troponin levels without contemporaneous ischaemic ECG changes. The mean, median and maximum recorded troponin levels are shown in Table 2.

Of the 121 patients with at least one troponin $\mathrm{T}$ measurement $\geq 15 \mathrm{ng} / \mathrm{L}, 66(46 \%)$ were in the range 15 to $100 \mathrm{ng} / \mathrm{L}$, while 55 patients (38\%) had at least one measurement $>100 \mathrm{ng} / \mathrm{L}, 24$ patients $(20 \%)$ had at least one normal troponin measurement during study followup and only 7 (5.8\%) had a normal troponin on admission to ICU. None of the patients with definite MI had a normal troponin on ICU admission.

Patients with raised troponin levels were older (mean age 65.8 versus $45.4, P<0.001)$ and had higher severity of illness scores on admission to ICU (mean APACHE II score 20.6 versus $13.2, P<0.001)$ than those without. Hypertension, vascular disease and diabetes were significantly more common in patients with elevated troponin levels compared to those without a troponin rise but there was no significant difference in the prevalence of IHD (Table 1).

\section{Outcomes}

Patients who had an elevated troponin on admission to ICU had a significantly higher ICU and hospital mortality compared to those without (27\% versus $3.3 \%, P=0.003$, and $36 \%$ versus $3.3 \%, P<0.001$, respectively). Patients with a possible or definite MI during their stay in ICU had a higher ICU, hospital and 180-day mortality compared to those with elevated troponin levels without contemporaneous ischaemic ECG changes; however, the differences were statistically not significant (Table 3).

There was no statistically significant difference in length of stay in ICU and hospital between the different troponin cohorts (Table 3).

\section{Comparison between clinically recognised and unrecognised myocardial events}

Only $12(20 \%)$ of the 59 study-identified definite and possible MIs were suspected by the clinical team caring for the patient (Table 4). There was no significant difference in mortality between clinically recognised and unrecognised MIs, although the number of clinically recognised events was small. Length of ICU and hospital stay were longer in those with a recognised MI compared to patients who had an MI which remained unrecognised (median of 17 versus 7 days for ICU stay, and 51 versus 18 days for hospital stay); the differences were still significant after adjustment for baseline risk factors ( $P=0.024$ and $P=0.030$, respectively).

Of the 12 patients with a clinically recognised MI, all had their troponin measured by the clinical team. Treatment for an ACS was started in three patients, echocardiography was performed in three, two were referred to cardiology for coronary angiography and one patient was started on a glyceryl trinitrate infusion.

\section{Association with sepsis and vasopressor use}

On the first day in ICU, 105 patients (73\%) satisfied $\geq 2$ criteria for SIRS. During their stay in ICU, 104 (72\%) patients were septic. The diagnosis of sepsis was associated with increased ICU mortality (28\% versus $8 \%)$ and increased hospital mortality (35\% versus $15 \%$ ).

Treatment with one or more inotropic or vasoactive drug was necessary in 86 patients of whom $98 \%$ received norepinephrine and 6 patients were on two or more medications. Use of vasoactive drugs was associated with both ICU and hospital mortality (37\% versus $2 \%$, and $44 \%$ versus $7 \%$, respectively).

On the day of troponin rise, 100 patients $(69 \%)$ had sepsis. Their ICU mortality was $28 \%$ compared to $9 \%$ in patients who were not septic when they had an elevated troponin level. On the day of troponin elevation, 84 patients (58\%) were receiving vasopressors. Their ICU mortality was $37 \%$ compared to $2 \%$ in patients who were not on vasopressors.

Among patients with a possible or definite MI, 68\% of patients were septic and $63 \%$ were on vasopressors on the day when the criteria for MI were fulfilled, with similar proportions in those with a definite and possible MI. Only $30 \%$ of patients who never had a troponin rise

Table 2 Summary of troponin T levels in all patients over the whole study period

\begin{tabular}{llllll}
\hline \multirow{2}{*}{ Group } & & \multicolumn{2}{l}{ Troponin T levels (ng/L) } \\
\cline { 3 - 6 } & N & Mean (SD) & Median* & $\begin{array}{l}\text { Minimum of all observations } \\
\text { across all days }\end{array}$ & $\begin{array}{l}\text { Maximum of all observations } \\
\text { across all days }\end{array}$ \\
\hline Definite MI & 20 & $214(306)$ & 73 & 9 & 3,093 \\
Possible MI & 39 & $229(416)$ & 63 & 5 & 3,335 \\
Elevated troponin T only & 62 & $97(138)$ & 55 & 0 & 1,337 \\
Normal & 23 & $3.3(3.5)$ & 2.4 & 0 & 14 \\
ALL & 144 & $133(271)$ & 45 & 0 & 3,335 \\
\hline
\end{tabular}

MI, myocardial infarction; SD, standard deviation.

*Mean and median are of the patients' mean troponin levels across follow-up period in each group. (Note that this summary of data serves to illustrate the patients' average troponin levels across follow-up period and are not used in the analyses of patient outcomes). 
Table 3 Outcome according to MI category

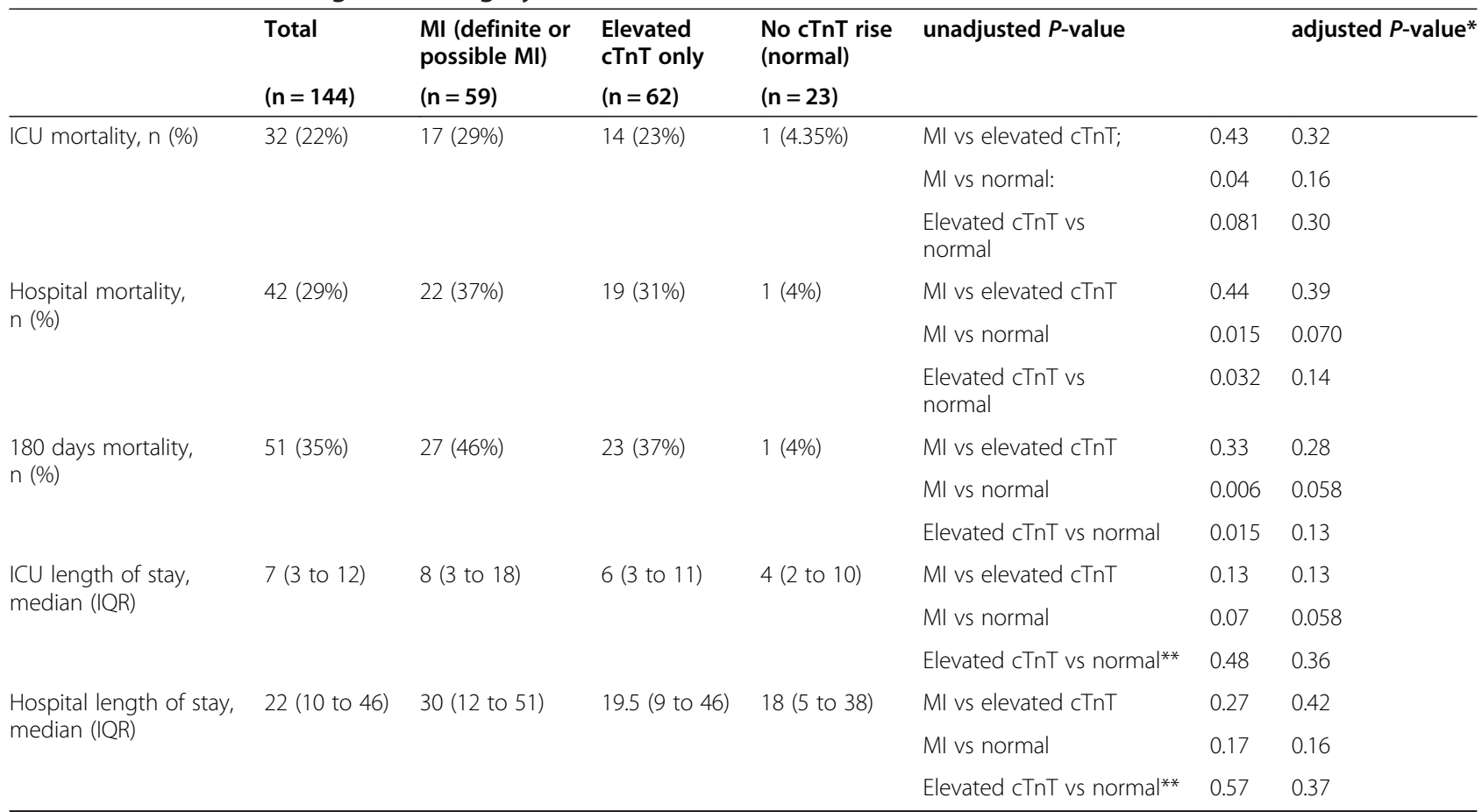

CTnT, cardiac troponin T; ICU, intensive care unit; IQR, inter-quartile range; MI, myocardial infarction.

*adjusted for age, APACHE II score, hypertension, diabetes and any type of vascular disease (reduced to two principal components in the regression models). **estimates based on log-transformed outcomes.

received vasopressor treatment at some stage during their stay in ICU.

\section{Discussion}

This study confirms that raised troponin levels are very common among critically ill patients admitted to ICU for non-cardiac reasons and are associated with an increased mortality up to 180 days. The large majority of ICU patients (84\%) had one or more elevated troponin values and $41 \%$ met the criteria for MI. Only $20 \%$ of definite MIs were recognised by the clinical team.
Previous studies have reported a wide range in prevalence of troponin elevation in critically patients. A metaanalysis by Lim et al. showed that in 20 studies, elevated troponin was found in a median of $43 \%$ (IQR 21\% to 59\%) of 3,278 patients [3]. Prevalences of 51 to $62 \%$ were reported in three studies $[7,14,15]$. However, these studies used a variety of different assays, thresholds to define elevation and measurement frequencies, and patient groups varied, making direct comparison impossible. Both Reynolds et al. and Audimooolam et al. used a troponin I assay with a cut-off at or near the 99th percentile whereas Lim et al. used troponin $\mathrm{T}$ at a cut-off higher

Table 4 Comparison between cardiac events recognised by clinical teams and unrecognised events

\begin{tabular}{|c|c|c|c|c|}
\hline & $\begin{array}{l}\text { Recognised MI } \\
\text { (definite or possible MI) }(n=12)\end{array}$ & $\begin{array}{l}\text { Not recognised MI } \\
\text { (definite or possible MI) }(n=47 \text { ) }\end{array}$ & $\begin{array}{l}\text { unadjusted } \\
P \text {-value* }\end{array}$ & $\begin{array}{l}\text { adjusted } \\
P \text {-value*** }\end{array}$ \\
\hline ICU mortality, n (\%) & $2(17 \%)$ & $15(32 \%)$ & 0.31 & 0.22 \\
\hline Hospital mortality, n (\%) & $3(25 \%)$ & $19(40 \%)$ & 0.33 & 0.24 \\
\hline 180 days mortality, n (\%) & $5(42 \%)$ & $22(47 \%)$ & 0.75 & 0.52 \\
\hline ICU length of stay, median (IQR) & 14.5 (8.5 to 20$)$ & 7 (3 to 14$)$ & $0.030^{* * *}$ & $0.024^{* * *}$ \\
\hline Hospital length of stay, median (IQR) & 48.5 (35.5 to 63.5$)$ & 24 (11 to 42$)$ & $0.038^{* * *}$ & $0.030^{* * *}$ \\
\hline
\end{tabular}

$\mathrm{ICU}$, intensive care unit; IQR, inter-quartile range; MI, myocardial infarction.

*P-value from unadjusted regression model where group was recognised and not recognised.

**P-value from adjusted regression model where group was recognised and not recognised; adjusted variables were age, APACHE II score, hypertension, diabetes and any type of vascular disease (reduced to two principal components in regression models).

***estimates based on log transformed outcome. 
than the $99^{\text {th }}$ percentile $[7,14,16]$. It is possible that troponin $\mathrm{T}$ is more frequently elevated at the $99^{\text {th }}$ percentile than troponin I in critically ill patients, potentially due to renal dysfunction [17].

The exact prevalence of real myocardial infarction in critically ill patients is also not known. Lim and colleagues found that $25.8 \%$ of all patients in a single mixed medicalsurgery ICU had an MI when assessed by clinicallyindicated investigations but prevalence was higher at $36 \%$ when using protocol-driven screening investigations $[2,14]$. A study of 26 septic surgical ICU patients reported a $26.9 \%$ prevalence of ischaemic ECG and troponin elevation and a further 7.7\% with indeterminate ECG changes [18]. Our study in selected patients who were admitted for noncardiac reasons revealed a $41 \%$ prevalence of possible and definite MIs.

One notable finding of our study, which mirrors that of Lim et al. and others [14,19], is that only $20 \%$ of study-diagnosed MIs were recognised by the clinical team and mortality was no different between recognised and unrecognised events. Diagnosing an MI in critically ill patients is not straightforward. There are no specific guidelines on the interpretation of ECG changes during critical illness and the reliability of ECG interpretation in critically ill patients for the detection of myocardial ischemia is uncertain. Similarly, there are no separate guidelines for patients with renal impairment. The most recent expert consensus guideline for the Universal Definition of Myocardial Infarction acknowledges that "it is often a challenge for the clinician, caring for a critically ill patient with severe single organ or multi-organ pathology, to decide on a plan of action when the patient has elevated cardiac troponin values" [1].

Relatively little research has focused on the patterns of ECG changes and their interpretation. Lim et al. established that there was only modest agreement between different operators interpreting the same ECG when they were not provided with other contextual information (troponin measurements, clinical history) [20]. Mehta et al. performed a study in 121 patients with sepsis and asked two independent assessors to analyse the ECGs without knowledge of troponin levels [21]. Inter-rater agreement for ischaemia was fair but improved when the troponin results were revealed to them. To our best knowledge, there are no published studies correlating infarct-characterising ECG changes in ICU patients with angiography-proven coronary artery disease. The problem is confounded further by the fact that critically ill patients can display classic ST elevation in the absence of a troponin elevation, for instance, in the context of intracranial haemorrhage [22].

Ammann et al. demonstrated, with echocardiography or autopsy as appropriate, that $70 \%$ of patients with troponin elevation did not have significant coronary artery disease
[23]. However, documented IHD (that is, previously known and recorded at admission) is common in ICU patients in general, as it was in our study group [24].

Several previous papers confirmed that troponin elevation is associated with increased ICU and hospital mortality in critically ill patients [3,5,23,25-29]. Our data demonstrate that the increased risk of dying persists even after discharge from hospital up to at least 180 days with no statistically significant difference between possible and definite MIs. Several potential mechanisms might explain troponin release in critically ill patients. These include demand ischaemia with or without a degree of coronary vasospasm, the effects of catecholamines and sepsis on the myocardium causing membrane leak and microscopic circulatory thrombosis or maldistribution. We noted that patients with MI had higher median and maximum troponin levels than those with troponin elevations alone without contemporaneous ECG changes. Mortality was low in patients who had normal troponin measurements throughout their ICU admission. We also found that significantly more patients with a possible or definite MI were receiving vaso-active drugs at the time of elevated troponin levels compared to patients who did not have a troponin rise. These findings support the hypothesis that a proportion of patients with a troponin rise may indeed have suffered from critical coronary artery disease and the acute illness, sepsis and/or treatment with catecholamines may have acted as a "stress test" and identified a cohort of patients with a very high risk of dying in six months.

The strengths of this study include the selection of patients who were admitted for non-cardiac reasons and the ECG interpretation by two senior cardiologists with adjudication by a third cardiologist in case of disagreement. Patients were also followed for 180 days which is longer than in previous studies.

It is important to acknowledge some limitations, too. Firstly, we conducted a single centre study. Although we enrolled more patients than the majority of previous studies, we were limited in our subgroup analyses by patient numbers. Our recording of smoking history was incomplete, and we did not collect any information on the use of cardio-protective medication. Finally, we were unable to perform Kaplan-Meier analyses and do not know the exact causes of death.

\section{Clinical implications and future work}

In view of the important association between troponin elevation and mortality in patients admitted to ICU without a primary cardiac diagnosis, and the high number of myocardial events which were not recognised by the clinical team, more work is necessary to improve the understanding of the aetiology of troponin increases. It is also necessary to explore whether there is a role for screening and targeted interventions. Although cardio- 
protective drugs and invasive strategies (coronary angiography and percutaneous intervention) have a clear role in the patient with ACS outside of the ICU, their role in critically ill patients with a raised troponin is still unclear. Many ICU clinicians do not routinely perform either troponin measurement or regular ECGs in patients without a cardiac diagnosis on admission. Our results show that daily troponin measurement in conjunction with regular ECGs may identify patients at high short- and longer-term risk in whom medical treatment according to an ACS protocol and appropriate diagnostic work-up may be beneficial.

\section{Conclusions}

Myocardial infarction is common amongst critically ill patients, is poorly diagnosed and associated with significant short- and long-term mortality. Further research is warranted to characterise better the underlying aetiology of the troponin rise in critically ill patients and to assess the impact of routine screening and targeted interventions.

\section{Key messages}

- Myocardial infarction is common in critically ill patients but poorly recognized in clinical practice.

- Myocardial infarction during critical illness is associated with a significantly increased risk of dying in up to 180 days.

- More work is necessary to evaluate the benefit of routine screening for myocardial infarction and the benefit of targeted interventions.

\begin{abstract}
Abbreviations
ACS: Acute coronary syndrome; APACHE: Acute Physiology and Chronic Health Evaluation; cTn: Cardiac troponin; CTnT: Troponin T; ECG: Electrocardiogram; ICU: Intensive care unit; IQR: Inter-quartile range; IHD: Ischaemic heart disease; MI: Myocardial infarction; REC: Research ethics committee; SD: Standard deviation; SIRS: Systemic inflammatory response syndrome.
\end{abstract}

\section{Competing interests}

The authors declare that they have no competing interests.

\section{Authors' contributions}

$\mathrm{DT}, \mathrm{DB}$ and $\mathrm{MO}$ designed the protocol and led the research project. $\mathrm{KL}$, JS and $\mathrm{BS}$ recruited patients and collected the necessary specimens and ECGs. PC and ET performed the laboratory analyses. JCo, JCh and IW analysed the ECGs. DT and MO retrospectively reviewed the medical notes. JP and $J$ performed the statistical analyses. AG and MT helped with the data interpretation. MT wrote the first draft. All authors helped to draft the manuscript. All authors apart from DB read and approved the final manuscript. DB died before the final manuscript was submitted.

\section{Acknowledgement}

This paper was written in honour of Professor David Bennett who died on 21 February 2012. He was a great colleague, mentor and friend and is deeply missed.

\section{Author details}

'Department of Critical Care, King's College London, Guy's \& St Thomas' Foundation Hospital, London, UK. 'King's College London, Division of Health and Social Care Research, London, UK. ${ }^{3} \mathrm{NIHR}$ Biomedical Research Centre at Guy's and St Thomas' NHS Foundation Trust and King's College London, London, UK. ${ }^{4}$ Croydon University Hospital, Surrey, UK. ${ }^{5}$ Department of Cardiology, Guy's \& St Thomas' Foundation Hospital, London, UK. ' St George's University Hospital, Clinical Blood Sciences, London, UK.

Received: 29 July 2013 Accepted: 27 March 2014

Published: 4 April 2014

\section{References}

1. Thygesen K, Alpert JS, Jaffe AS, Simoons ML, Chaitman BR, White HD, Joint ESC/ACCF/AHA/WHF Task Force for the Universal Definition of Myocardial Infarction, Katus HA, Lindahl B, Morrow DA, Clemmensen PM, Johanson P, Hod H, Underwood R, Bax JJ, Bonow RO, Pinto F, Gibbons RJ, Fox KA, Atar D, Newby LK, Galvani M, Hamm CW, Uretsky BF, Steg PG, Wijns W, Bassand $J P$, Menasché P, Ravkilde J, Ohman EM, Antman EM, et al: Third universal definition of myocardial infarction. Circulation 2012, 126:2020-2035.

2. Lim W, Holinski P, Devereaux PJ, Tkaczyk A, McDonald E, Clarke F, Qushmaq I, Terrenato I, Schunemann H, Crowther M, Cook D: Detecting myocardial infarction in critical illness using screening troponin measurements and ECG recordings. Crit Care 2008, 12:R36.

3. Lim W, Cook DJ, Griffith LE, Crowther MA, Devereaux PJ: Elevated cardiac troponin levels in critically ill patients: prevalence, incidence, and outcomes. Am J Crit Care 2006, 15:280-288.

4. Bessiere F, Khenifer S, Dubourg J, Durieu I, Lega JC: Prognostic value of troponin in sepsis: a meta-analysis. Intensive Care Med 2013, 39:1181-1189.

5. Hamilton MA, Toner A, Cecconi M: Troponin in critically ill patients. Minerva Anestesiol 2012, 78:1039-1045.

6. Landesberg G, Vesselov Y, Einav S, Goodman S, Sprung CL, Weissman C: Myocardial ischemia, cardiac troponin, and long-term survival of high-cardiac risk critically ill intensive care unit patients. Crit Care Med 2005, 33:1281-1287.

7. Audimooolam VK, MCPhail MJ, Sherwood R, Willars C, Bernal W, Wendon JA, Auzinger G: Elevated troponin I and its prognostic significance in acute liver failure. Crit Care 2012, 16:R228.

8. Lim W, Whitlock R, Khera V, Devereaux PJ, Tkaczyk A, Heels-Ansdell D, Jacka M, Cook D: Etiology of troponin elevation in critically ill patients. J Crit Care 2010, 25:322-328.

9. Agewall $\mathrm{S}$, Giannitsis $\mathrm{E}$, Jernberg $\mathrm{T}$, Katus $\mathrm{H}$ : Troponin elevation in coronary vs. non-coronary disease. Eur Heart J 2011, 32:404-411.

10. Wu AH: Increased troponin in patients with sepsis and septic shock: myocardial necrosis or reversible myocardial depression? Intensive Care Med 2001, 27:959-961.

11. Maeder M, Fehr T, Rickli H, Amman P: Sepsis-associated myocardial dysfunction: diagnostic and prognostic impact of cardiac troponins and natriuretic peptides. Chest 2006, 129:1349-1366.

12. Ver Elst KM, Spapen HD, Nguyen DN, Garbar C, Huyghens LP, Gorus FK: Cardiac troponins I and T are biological markers of left ventricular dysfunction in septic shock. Clin Chem 2000, 46:650-657.

13. Klein Gunnewiek JM, van de Leur JJ: Elevated troponin T concentrations in critically ill patients. Intensive Care Med 2003, 29:2317-2322.

14. Lim W, Qushmaq I, Cook DJ, Crowther MA, Heels-Ansdell D, Devereaux PJ, Troponin T Trials Group: Elevated Troponin and myocardial infarction in the intensive care unit: a prospective study. Crit Care 2005, 9(6):R636-644.

15. Collinson PO, Heung YM, Gaze D, Boa F, Senior R, Christenson R, Apple FS: Influence of population selection on the 99th percentile reference value for cardiac troponin assays. Clin Chem 2012, 58:219-225.

16. Reynolds T, Cecconi M, Collinson P, Rhodes A, Grounds RM, Hamilton MA: Raised serum cardiac troponin I concentrations predict hospital mortality in intensive care unit patients. Br J Anaesth 2012, 109:219-224.

17. Aviles RJ, Askari AT, Lindahl B, Wallentin L, Jia G, Ohman EM, Mahaffey KW, Newby LK, Califf RM, Simoons ML, Topol EJ, Berger P, Lauer MS: Troponin T levels in patients with acute coronary syndromes, with or without renal dysfunction. N Engl J Med 2002, 346:2047-2052.

18. Spies C, Haude V, Fitzner R, Schröder K, Overbeck M, Runkel N, Schaffartzik W: Serum cardiac troponin T as a prognostic marker in early sepsis. Chest 1998, 113:1055-1063. 
19. Guest TM, Ramanathan AV, Tuteur PG, Schechtman KB, Ladenson JH, Jaffe AS: Myocardial injury in critically ill patients. A frequently unrecognized complication. JAMA 1995, 273:1945-1949.

20. Lim W, Qushmaq I, Cook DJ, Devereaux PJ, Heels-Ansdell D, Crowther MA, Tkaczyk A, Meade MO, Cook DJ: Reliability of electrocardiogram interpretation in critically ill patients. Crit Care Med 2006, 34:1338-1343.

21. Mehta S, Granton J, Lapinsky SE, Newton G, Bandayrel K, Little A, Siau C, Cook DJ, Ayers D, Singer J, Lee TC, Walley KR, Storms M, Cooper J, Holmes CL, Hebert P, Gordon AC, Presneill J, Russell JA, Vasopressin and Septic Shock Trial (VASST) Investigators: Agreement in electrocardiogram interpretation in patients with septic shock. Crit Care Med 2011, 39:2080-2086.

22. Rennyson SL, Hunt J, Haley MW, Norton HJ, Littmann L: Electrocardiographic ST-segment elevation myocardial infarction in critically ill patients: an observational cohort analysis. Crit Care Med 2010, 38:2304-2309.

23. Ammann P, Maggiorini M, Bertel O, Haenseler E, Joller-Jemelka HI, Oechslin E, Minder El, Rickli H, Fehr T: Troponin as a risk factor for mortality in critically ill patients without acute coronary syndromes. J Am Coll Cardiol 2003, 41:2004-2009.

24. Walsh TS, McClelland DB, Lee RJ, Garrioch M, Maciver CR, McArdle F, Crofts SL, Mellor I, ATICS Study Group: Prevalence of ischaemic heart disease at admission to intensive care and its influence on red cell transfusion thresholds: multicentre Scottish Study. Br J Anaesth 2005, 94:445-452.

25. Stein R, Gupta B, Agarwal S, Golub J, Bhutani D, Rosman A, Eng C: Prognostic implications of normal $(<0.10 \mathrm{ng} / \mathrm{ml})$ and borderline ( 0.10 to $1.49 \mathrm{ng} / \mathrm{ml}$ ) troponin elevation levels in critically ill patients without acute coronary syndrome. Am J Cardiol 2008, 102:509-512.

26. Babuin L, Vasile VC, Rio Perez JA, Alegria JR, Chai HS, Afessa B, Jaffe AS: Elevated cardiac troponin is an independent risk factor for short- and long-term mortality in medical intensive care unit patients. Crit Care Med 2008, 36:759-765

27. Vasile VC, Babuin L, Rio Perez JA, Alegria JR, Song LM, Chai HS, Afessa B, Jaffe AS: Long-term prognostic significance of elevated cardiac troponin levels in critically ill patients with acute gastrointestinal bleeding. Crit Care Med 2009, 37:140-147.

28. Wu TT, Yuan A, Chen CY, Chen WJ, Luh KT, Kuo SH, Lin FY, Yang PC: Cardiac troponin I levels are a risk factor for mortality and multiple organ failure in noncardiac critically ill patients and have an additive effect to the APACHE II score in outcome prediction. Shock 2004, 22:95-101.

29. Relos RP, Hasinoff IK, Beilman GJ: Moderately elevated serum troponin concentrations are associated with increased morbidity and mortality rates in surgical intensive care unit patients. Crit Care Med 2003, $31: 2598-2603$

doi:10.1186/cc13818

Cite this article as: Ostermann et al:: A prospective study of the impact of serial troponin measurements on the diagnosis of myocardial infarction and hospital and six-month mortality in patients admitted to ICU with non-cardiac diagnoses. Critical Care 2014 18:R62.

\section{Submit your next manuscript to BioMed Central and take full advantage of:}

- Convenient online submission

- Thorough peer review

- No space constraints or color figure charges

- Immediate publication on acceptance

- Inclusion in PubMed, CAS, Scopus and Google Scholar

- Research which is freely available for redistribution

Submit your manuscript at www.biomedcentral.com/submit 